\title{
The Research on Basic Properties, Legal Characteristics and Improvement Measures of Format Contract
}

\author{
Jing Jia, Chao Feng and Chaomin Jiao \\ State Grid Baoding Electric Power Supply Company, Baoding 071051, China; \\ ygzxyz@163.com
}

Keywords: format contract, characteristics of law, Legislative regulation

\begin{abstract}
Format contract is one of the most important and common types in the field of contract. The wide use of it has brought great convenience to people's life, but also made a number of social problems. Therefore, it is a difficult task for us to strengthen the legal control of the format contract to protect the fairness and justice and protect the legitimate rights and interests of consumers. In this paper, first, the concept, the legal characteristics and the nature of format contract are described and it can be determined that the format contract is essentially a form of contract. Then, from two aspects of the positive and negative aspects of the format, discussion on the convenience and disadvantages of the format contract to the social life has been made, which is very worth our thinking and discussion. Finally, in order to improve the punishment mechanism of format contract, with the legislative regulation as the main body, the format contract control mode is put forward combined with the judicial regulation, administrative regulation and self-regulation. Besides, the establishment of the special law of the format contract has also been preliminarily conceived in this paper.
\end{abstract}

\section{Introduction}

Perhaps people have not yet realized that many of our daily life behavior will produce what kind of civil rights and obligations: When shopping in a mall, we may see the counter with notice of "goods sold are not returnable"; we may be charged extra in the hotel registration for a little late and we may find the ticket printed on the back of a dense note. When we enjoy the convenience of daily life we have also to reluctantly accept the conditions of the contract.

In this paper, the relevant problems of format contract are analyzed by law firstly, mainly including the concept, the legal characteristics and natures of the format contract. And then the advantages and disadvantages of the format contract are expounded. Finally, through the analysis and demonstration, the suggestion of perfecting the legal regulation system of the form contract has been put forward.

\section{Characteristics of the format contract}

\subsection{Basic characteristics of the format contract}

From the formulation of the habit, the format of the contract can be chose to use from different angles or in different occasions, which mainly depends on the individual's style of language and emphasis. And their use may differ: standard terms refers a part of the content with accessory but the format contract usually refers to the total content of the contract or the main content of the contract with accessory and that is to say that not all contracts can be called format contracts whose terms are all the standard terms. However, the terms of format and format contract should not be treated as completely different two concepts because of the existence of this difference. In essence, the terms of format or the format contract are only different representations of the same type of contract, referring the contract whose content is not allowed to be made any change, prepared by a party to deal with a particular majority of people. Although there may be differences in the scope, the legal rules and regulations of the two are the same.

\subsection{Legal characteristics of format contract}


1、 The offer of a form contract has universality and durability

The universality of the format contract refers to that the contract offer is not issued to the specific object, but to the majority of the people. The permanence of the format contract refers to the relative stability of the terms of the contract so that the contract has the legal effect in a long time.

2、 the terms of the format contract have features of unilateral decision in advance and no negotiation

The traditional way of concluding a contract mainly includes two stages: offer and acceptance, Both parties have equal status in the process and can express their willingness to contract. The final establishment of the contract should be based on the consistency of the two sides, which is the most traditional and the most classical way to conclude the contract law.

3、 Content of format contract is normative and complete

The terms of the format contract has objectivity and scientific nature because it has been made after deliberate consideration and long time practice, which is also the specification requirements for format contract. The terms of the format contract are basically formulated by specialized agencies or people with special knowledge or organization and thus the formulation of the terms of the contract is relatively complete and has the greatest extent possible to reflect the needs of society, which is also a good embodiment of the completeness of format contract.

4、Format contract has the characteristic of express in writing

This is the difference between the format contract and the general ordinary contract. A general contract may be made in writing or in oral, while format contracts are generally printed in written. In principle, the parties presented the contract will clearly print the terms of the contract on a certain certificate or post it in the business place where is significant in order to make the other party understand.

5、 The status of the parties to the contract is not equal.

From the status of the parties to a format contract, the party has the absolute advantage in the economic status who formulated the terms and it also facilitates them impose upon other parties, which is manifested as a legal monopoly or a de facto monopoly on the format contract. It can be seen that the party formulated the terms will be in a dominant position, while the relative side is in a subordinate position.

6、 The format contract can be reused in the application.

In real life, extensive use of the format contract makes the transaction more efficient life more convenient, reflecting the characteristic of reusability of format contract. Format contracts are formulated in order to be used repeatedly. It is the characteristics of repeated use that we need to develop the format of the contract, otherwise it will lose its meaning.

\subsection{The nature of the contract format}

In essence, the form contract is only one kind of contract, the parties still have the right to conclude or not to conclude the contract and it mainly has the following several aspects of the nature:

1、 The format contract is still an offer - commitment form.

2、 Counterpart has the rights to enjoy the freedom of choice.

3、 In the legal status, parties are still equal.

4、 Format of the contract is still make debt as the main content.

\subsection{Positive roles and negative effects of format contract}

1、 Positive roles of format contract

Since its inception, in exchange field, format contract with its strong vitality has got the rapid development and now play an important role in people's daily lives. It has also become a form of exchange in many fields of mainstream, whose positive role can not be compared.

First of all, using the format contract can speed up the transaction and reduce the time and cost of the transaction. Format contract can be used repeatedly in the drawn up which saves the time of consultations, making the time of the contract faster, it is conducive to reduce transaction costs and improve transaction efficiency. 
Secondly, the format contract is generally developed from the industry experts, who can predict the various problems that may arise in the format contract and make the corresponding provisions on the burden of the rights and obligations and the distribution of the risk in the clause content.

Besides, the format contract is generally used in written form, containing the clear and detailed terms, which can make up the lack of expertise knowledge of relative person.

Fourth, the modern market economy requires the contract can be regulated. Persistence of offer and non negotiation of format contract meet the needs of the state for policy regulation.

2、 Negative effects of format contract

At present, more and more industry use format contract and there are a considerable number of civil legal relationship based on the format of the contract, format contract has been widely used and almost penetrated into all aspects of social life. According to statistics, in the more than $90 \%$ of the sales of goods industry and services industry, clear rights and obligations will be expressed in the form of format contract. Especially in the post and telecommunications, housing sales and other industries, the ratio is close to $100 \%$. But all sorts of drawbacks in the format contract also infringe upon the rights and interests of consumers.

For example, in small and medium-sized cities, property companies often put together the property management fees and water and usually cut the supply of water and electricity of the home owners who refused to pay the property management fee. In fact, the use of water is a legal relationship with the water company, Electricity is a legal relationship with power supply company, the use of gas is legal relationship with the gas company, and so is the property management fee. There are differences in the subject of each legal relationship and these are basically different kinds of legal relations. After paying the water and electricity, we have the right to use water and electricity. Property companies have no right to cut the power or water supply. In this case, the charge mode of the property company is an obvious unfair terms and the practice exceeds the legal provisions of the rights and responsibilities of the operator, thus it is an invalid clause. Above example has reflected the negative side of the format contract and in real life problems become more prominent: some businesses through the format of the contract force consumers to accept service or unreasonable fees; in order to achieve the purpose of promoting they may fraud consumers; the use of the format contract may limit consumer rights to diminished responsibility of the operator's .These have seriously damaged the interests of consumers.

\section{Suggestions on improving the legal regulation system of the format contract}

The provisions of the format contract shall be gradually improved based on the existing mature experience at home and abroad and combined with the actual situation and the level of development to make the format contract really for the people. There are some suggestions:

1、 Speed up the legislative improvement;

2、 Strengthen the intensity of judicial control;

3、 Promote the participation of experts and scholars;

4. Give the administrative organs of industry and commerce at all levels of supervision and inspection rights and establish a sound format contract ex ante audit system;

5、 Improve the quality of judicial personnel and strengthen the construction of law enforcement team;

6、 Improve citizens' awareness of rights and active role in the supervision of consumer organizations.

The improvement of relevant provisions of format contract is the key to the supervision and management. In a virtuous mechanism, the format contract can reduce the negative impact of its own disadvantages and can play a positive role in society. So the key to the use of the format contract is how we control and grasp it correctly. 


\section{Summary}

Format contract is the product of the development of commodity economy and has brought the incomparable convenience for our daily life today. But its inherent defects, contrary to the principle of freedom has also been controversial. We have to face the fact that on the one hand, the format of the contract is efficient and convenient, on the other hand, unfair and unreasonable terms of the contract infringement the rights and interests of consumers all the time. How to resolve this contradiction, in other words, how to make full use of the positive side of the format contract while regulate its negative side is the problem we need to solve urgently. In recent years, these unfair format contract terms are not under control and there is a trend of increasing legitimacy. And many unfair forms of contract terms are often found a legal basis in government regulations. In view of this situation, we put forward the relevant suggestions to improve the legal regulation system of the format contract, which is conducive to improve the regulatory system of the form contract.

\section{References}

[1]. George O. White III, Jean J. Boddewyn, Roberto Martin N. Galang. Legal system contingencies as determinants of political tie intensity by wholly owned foreign subsidiaries: Insights from the Philippines. Journal of World Business, Vol. 50 (2015), No. 2, p. 342-356.

[2]. Carmine Guerriero. Endogenous legal traditions and economic outcomes. Journal of Comparative Economics, Vol. 44 (2016), No. 2, p. 416-433.

[3]. Henrik Lando. Optimal rules of negligent misrepresentation in insurance contract law. International Review of Law and Economics, Vol. 46 (2016), p. 70-77.

[4]. Osnat Jacobi, Avi Weiss. Allocation of fault in contract law. International Review of Law and Economics, Vol. 36 (2013), p. 1-11.

[5]. Josep Maria Bech Serrat. Quality of hotel service and consumer protection: A European contract law approach. Tourism Management, Vol. 32 (2011), No. 2, p. 277-287.

[6]. Yu-Fu Chen, Michael Funke. China's new Labour Contract Law: No harm to employment? China Economic Review, Vol. 20 (2009), No. 3, p. 558-572.

[7]. Robert J. Gary-Bobo, Touria Jaaidane. Strikes and slowdown in a theory of relational contracts. European Journal of Political Economy, Vol. 36 (2014), p. 89-116.

[8]. Zhuo Feng, Shui-Bo Zhang, Ying Gao. On oil investment and production: A comparison of production sharing contracts and buyback contracts. Energy Economics, Vol. 42 (2014), p. 395-402.

[9]. Krishnamurthy V. Subramanian, Frederick Tung. Law and Project Finance. Journal of Financial Intermediation, Vol. 25 (2016), p. 154-177.

[10]. Sean Masaki Flynn, Michael Donnelly. Does labor contract completeness drive unionization? Experimental evidence. The Journal of Socio-Economics, Vol. 41 (2012), No. 4, p. 445-454. 